\title{
Patients with Sore Throat: A Survey of Self-Management and Healthcare-Seeking Behavior in 13 Countries Worldwide
}

This article was published in the following Dove Press journal: Pragmatic and Observational Research

\author{
Alike W van der Velden' \\ Aurelio Sessa ${ }^{2}$ \\ Attila Altiner ${ }^{3}$ \\ Antonio Carlos Campos Pignatari (iD 4 \\ Adrian Shephard ${ }^{5}$ \\ 'Julius Center for Health Sciences and \\ Primary Care, University Medical Center \\ Utrecht, Utrecht, The Netherlands; \\ ${ }^{2}$ Italian College of General Practitioners \\ and Primary Care, Florence, Italy; \\ ${ }^{3}$ Institute of General Practice, Rostock \\ University Medical Center, Rostock, \\ Germany; ${ }^{4}$ Paulista School of Medicine \\ (EPM), Federal University of São Paulo \\ (UNIFESP), São Paulo, Brazil; ${ }^{5}$ Reckitt \\ Benckiser Healthcare Ltd, Slough, UK
}

Correspondence: Alike $\mathrm{W}$ van der Velden Julius Center for Health Sciences and Primary Care, University Medical Center Utrecht, STR 6.103, P.O. Box 85500, Utrecht, GA 3508, The Netherlands Email A.W.vanderVelden@umcutrecht.nl
Background: Acute sore throat is one of the most common problems for which patients consult their general practitioner and is a key area for inappropriate antibiotic prescribing. The objective of this study was to investigate patients' attitudes related to healthcare-seeking behavior and self-management of sore throat.

Methods: We conducted an observational, questionnaire-based study across 13 countries (Australia, Brazil, China, France, Germany, Italy, the Philippines, Russia, Saudi Arabia, South Africa, Thailand, the UK and the USA) on respondents who reported having had a sore throat in the previous 12 months. Data were collected on their experiences, contact with healthcare professionals, treatment practices and opinions about antibiotics.

Results: A total of 5196 respondents (approximately 400 per country) completed the survey. Over $80 \%$ of respondents sought advice for a sore throat, with $30 \%$ consulting a general practitioner. The desire to limit the worsening of symptoms was the main reason for seeking treatment. Other reasons concerned resolving persistent symptoms and reducing the impact on daily life/sleep. Self-management for sore throat was mainly medicated sore throat remedies. "Wanting an antibiotic" was rated much lower (55\%) than most other reasons for visiting a doctor, but this differed greatly between countries. The percentage of respondents using antibiotics varied widely, for example, $10 \%$ in the UK and $45 \%$ in Saudi Arabia. There was considerable variation in the proportion of respondents who thought that antibiotics would be effective against sore throat (from $24 \%$ in France to $94 \%$ in Saudi Arabia).

Conclusions: Our findings suggest that knowledge of effective treatments for sore throat varied widely. The results of this study should enable healthcare professionals to better anticipate patients' needs. This will support healthcare professionals in their role as antibiotic stewards, helping to reduce the misuse of antibiotics, and further guiding patients towards symptomatic self-management of sore throat.

Keywords: primary care, community health, disease management, health literacy, medications, pharmacy

\section{Introduction}

Inappropriate use and high consumption of antibiotics contribute to the development of bacterial resistance. ${ }^{1-3}$ Although hospitals are the focal points of antibioticresistance-related problems, ${ }^{4}$ antibiotic prescribing is greatest in the community setting. ${ }^{5}$ Rates of antibiotic prescribing in primary care vary widely worldwide, ${ }^{6}$ and there is a need to address inappropriate prescribing. ${ }^{7}$ 
Sore throat is a common acute problem for which patients consult their general practitioner (GP) ${ }^{8}$ Nearly half of all antibiotic prescriptions in the UK are related to treating respiratory tract and ear conditions: of these, sore throat accounts for $16.7 \%$ of prescriptions. ${ }^{9}$ However, antibiotics only offer modest benefits, as up to $80 \%$ of sore throats have a viral etiology, and the vast majority of sore throats are self-limiting. ${ }^{10,11}$

The drivers of antibiotic prescribing for sore throat are complex, including both doctor- and patient-related factors. GPs may prescribe antibiotics inappropriately for reasons such as perceived and real patient expectations and pressure, preserving the doctor-patient relationship, limited consultation time, diagnostic uncertainty and poor communication with patients. ${ }^{12-14}$ Furthermore, GPs may believe that antibiotic prescribing in primary care is not an important factor in the development of antibiotic resistance. $^{13,14}$ Although patient pressure is a driver of inappropriate antibiotic prescribing, patients with sore throat hoping for antibiotics may in fact want symptom relief, ${ }^{15}$ and benefit from reassurance and counseling on effective self-management options. ${ }^{16}$

This study aimed to investigate patient attitudes related to healthcare-seeking behavior and self-management of sore throat in 13 countries worldwide. Understanding what motivates patients to visit their GP and the types of treatments they prefer can be used to inform and encourage GPs to reduce the reliance on antibiotics for sore throat and utilize more effective strategies to improve symptomatic relief.

\section{Methods}

\section{Multinational Patient Survey}

An observational study was conducted across 13 countries: Australia (AUS), Brazil (BR), China (CH), France (FR), Germany (GE), Italy (IT), the Philippines (PH), Russia (RU), Saudi Arabia (KSA), South Africa (SA), Thailand (TH), the United Kingdom (UK) and the United States of America (USA), between November and December 2017. A questionnaire was designed to gather information regarding attitudes, experiences and management of sore throat (Supplementary File 1). In order to minimize heterogeneity between countries in their understanding of the questionnaire concepts, it was developed by researchers experienced in consumer health research across the different countries, with culturally appropriate translation as necessary. Participants were recruited from an online database of individual consumers maintained by Incite Marketing Planning (London, UK), in compliance with the Market Research Society's Code of Conduct. Participants provided their responses to an online questionnaire or face-to-face interview (Saudi Arabia only); those who answered 'Yes' to having a sore throat in the previous 12 months were included in this study. All responses in this non-interventional survey were collected anonymously, with written or verbal informed consent of participants. The survey used a proportional quota sampling method to ensure a representative sample of the general population. Quotas were set within each country for age, sex, income/social grade and region, and recruitment was open until targets were reached. Participants completed a 55-item questionnaire, including questions on their characteristics, experiences of sore throat, attitudes, contact with healthcare professionals (HCPs), treatment practices and opinions about antibiotics (approximate duration of survey: 30-45 minutes). Respondents were given a low-value points-based incentive for completing the survey. Those who worked in market research, journalism/media, drugstores/pharmacies or the manufacture of healthcare/pharmaceutical products, and healthcare/medical professionals were excluded.

\section{Data Analysis}

Data were analyzed using Microsoft Excel; percentages of responses are shown. The study was descriptive and statistical analysis was not employed. As the study was initiated as market research, no analysis plan was prepared prior to data collection.

\section{Results}

\section{Incidence, Duration, Severity and Understanding of Sore Throat}

A total of 5196 adults who experienced sore throat in the previous 12 months completed the survey. Demographic data are presented in Table 1. Respondents within each country were heterogeneous with respect to household incomes, social grades and geographical region (Supplementary File 2).

Almost half reported suffering with a sore throat three or four times a year while $18 \%$ reported having a sore throat every month of the year, but there was wide variability between countries (Table 2). Duration of sore throat was commonly reported to last for $2-5$ days, with $10 \%$ of participants reporting symptoms lasting for more than a 
Table I Demographic Data, Overall and per Country

\begin{tabular}{|c|c|c|c|c|c|c|c|c|c|c|c|c|c|c|}
\hline \multirow[t]{2}{*}{ Survey Item } & \multicolumn{14}{|c|}{ Responses } \\
\hline & Overall & AUS & BR & $\mathbf{C H}$ & $\mathbf{F R}$ & GE & IT & $\mathbf{P H}$ & RU & KSA & SA & TH & UK & USA \\
\hline Respondents, $\mathrm{N}$ & 5196 & 400 & 400 & 400 & 400 & 400 & 400 & 400 & 400 & 395 & 400 & 401 & 400 & 400 \\
\hline \multicolumn{15}{|l|}{ Sex, \% $(N=5 \mid 96)$} \\
\hline Female & 52 & 50 & 54 & 50 & 54 & 50 & 50 & 54 & 52 & 51 & 50 & 56 & 50 & 50 \\
\hline Male & 48 & 50 & 46 & 50 & 46 & 50 & 50 & 46 & 48 & 49 & 50 & 44 & 50 & 50 \\
\hline \multicolumn{15}{|c|}{ Age group in years, \% $(\mathrm{N}=5196)$} \\
\hline $18-34$ & 41 & 35 & 49 & 44 & 25 & 29 & 33 & 58 & 38 & 55 & 53 & 43 & 33 & 34 \\
\hline $35-49$ & 32 & 31 & 39 & 32 & 34 & 33 & 34 & 27 & 29 & 31 & 25 & 38 & 32 & 30 \\
\hline $50-70$ & 28 & 34 & 13 & 24 & 41 & 39 & 33 & 15 & 34 & 14 & 22 & 19 & 35 & 36 \\
\hline
\end{tabular}

Abbreviations: AUS, Australia; BR, Brazil; CH, China; FR, France; GE, Germany; IT, Italy; PH, the Philippines; RU, Russia; KSA, Saudi Arabia; SA, South Africa; TH, Thailand; UK, the United Kingdom; USA, the United States of America.

Table 2 Experience of Sore Throat

\begin{tabular}{|c|c|c|c|c|c|c|c|c|c|c|c|c|c|c|}
\hline \multirow[t]{2}{*}{ Survey Item } & \multicolumn{14}{|c|}{ Responses, \% } \\
\hline & Overall & AUS & $\mathbf{B R}$ & $\mathbf{C H}$ & $\mathbf{F R}$ & GE & IT & $\mathbf{P H}$ & $\mathbf{R U}$ & KSA & SA & TH & UK & USA \\
\hline \multicolumn{15}{|c|}{ Incidence of sore throat during the last year $(\mathrm{N}=5196)$} \\
\hline I-2 times a year & 34 & 38 & 37 & 14 & 39 & 38 & 31 & 37 & 33 & 30 & 36 & 27 & 43 & 36 \\
\hline $3-4$ times a year & 48 & 44 & 50 & 51 & 53 & 43 & 58 & 47 & 47 & 65 & 39 & 49 & 44 & 39 \\
\hline Every month of the year & 18 & 18 & 14 & 36 & 8 & 19 & 11 & 16 & 21 & 6 & 25 & 25 & 13 & 25 \\
\hline \multicolumn{15}{|c|}{ Duration of symptoms of most recent sore throat $(\mathrm{N}=5196)$} \\
\hline$\leq \mathrm{I}$ day & 15 & 23 & 14 & 13 & 9 & 13 & 6 & 14 & 12 & 35 & 15 & 7 & 13 & 21 \\
\hline $2-3$ days & 42 & 34 & 40 & 55 & 41 & 40 & 43 & 45 & 32 & 42 & $4 I$ & 43 & 45 & 42 \\
\hline 4-5 days & 24 & 19 & 21 & 23 & 32 & 26 & 30 & 22 & 30 & 17 & 25 & 25 & 20 & 17 \\
\hline 6-7 days & 10 & 10 & 12 & 6 & 9 & 10 & 13 & 8 & 15 & 6 & 7 & 15 & 9 & 7 \\
\hline$>7$ days & 10 & 14 & 13 & 4 & 10 & 11 & 9 & 13 & 12 & 1 & 13 & 9 & 14 & 14 \\
\hline \multicolumn{15}{|c|}{ Severity of most recent sore throat $(N=5196)^{a}$} \\
\hline $1-6$ & 54 & 63 & 53 & 48 & 60 & 59 & 52 & 63 & 57 & 21 & 54 & 60 & 60 & 52 \\
\hline $7-8$ & 37 & 32 & 34 & 41 & 36 & 36 & 45 & 33 & 34 & 45 & 38 & 35 & 34 & 34 \\
\hline $9-10$ & 9 & 6 & 13 & 11 & 4 & 5 & 4 & 4 & 10 & 35 & 8 & 4 & 6 & 14 \\
\hline
\end{tabular}

Note: "Sore throat scored on a I-10 severity scale, where I represents "very mild" and I0 represents "very severe".

Abbreviations: AUS, Australia; BR, Brazil; CH, China; FR, France; GE, Germany; IT, Italy; PH, the Philippines; RU, Russia; KSA, Saudi Arabia; SA, South Africa; TH, Thailand; UK, the United Kingdom; USA, the United States of America.

week (Figure 1). Over half of respondents (54\%) scored the severity of their symptoms between 1 and 6 on a $1-10$ severity scale. More participants from Saudi Arabia (80\%) rated their last sore throat severe (7-10 on the severity scale) than the cross-country average (46\%).

Knowing the cause of sore throat was considered important, particularly for those in the Philippines and Thailand (Table 3). When considering the cause of their most recent sore throat, the majority thought "they knew for sure" or had "a good idea". For these respondents, the "common cold/flu", another infection or environmental conditions were frequently cited as the cause.

\section{Self-Management}

Respondents were generally proactive when it came to seeking treatment or help with the symptoms of their sore throat (Table 4). The desire to limit the worsening of symptoms was the main reason for seeking treatment 


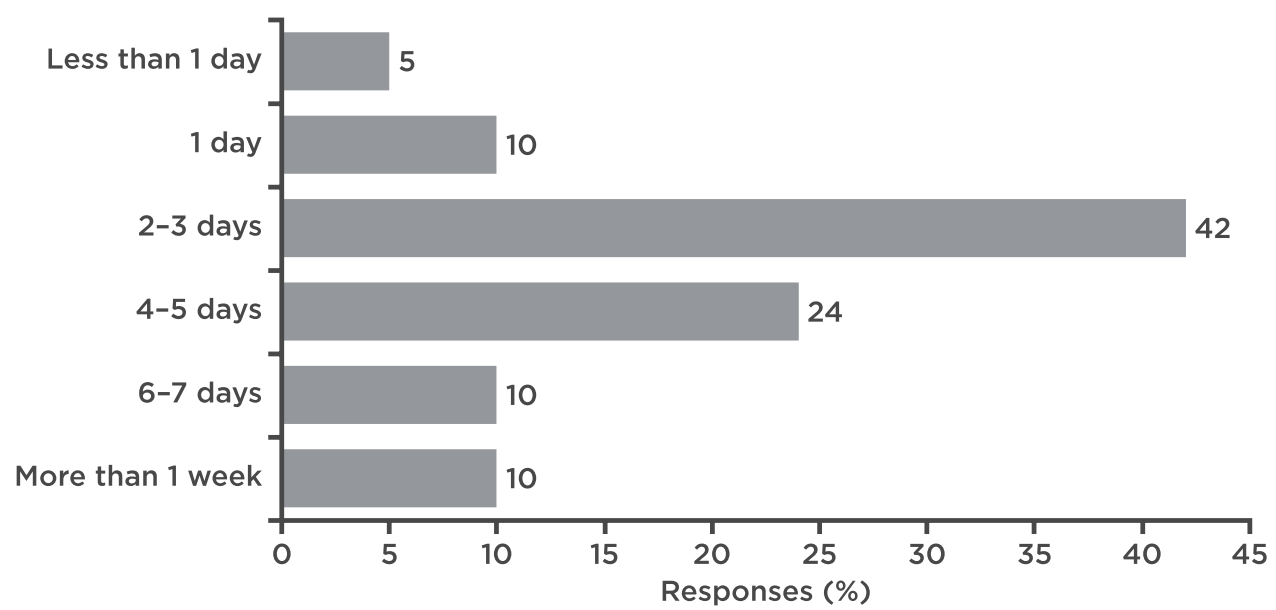

Figure I Duration of most recent sore and/or dry throat symptoms. Duration of symptoms for 5196 survey participants. Question: "Thinking about the most recent time you suffered a sore or dry throat, approximately how long did your symptoms last?" (single response allowed).

(48\%). Medicated sore throat remedies were the principal method of treatment for $36 \%$ of respondents, with antibiotics cited as the next most frequently used medication.

\section{Seeking Help/Advice}

Most respondents (81\%) reported seeking advice for their most recent sore throat. HCPs were the predominant

Table 3 Anticipated/Perceived Cause of Sore Throat

\begin{tabular}{|c|c|c|c|c|c|c|c|c|c|c|c|c|c|c|}
\hline \multirow[t]{2}{*}{ Survey Item } & \multicolumn{14}{|c|}{ Responses, \% } \\
\hline & Overall & AUS & $\mathbf{B R}$ & $\mathbf{C H}$ & $\mathbf{F R}$ & GE & IT & PH & RU & KSA & SA & TH & UK & USA \\
\hline \multicolumn{15}{|c|}{ Importance of knowing the cause of sore throat $(\mathrm{N}=5196)$} \\
\hline Fairly/very important & 82 & 71 & 91 & 91 & 65 & 73 & 87 & 97 & 78 & 91 & 79 & 95 & 66 & 81 \\
\hline Not very important & 15 & 24 & 7 & 8 & 30 & 24 & 12 & 3 & 20 & 7 & 19 & 4 & 28 & 16 \\
\hline Not at all important & 3 & 5 & 2 & I & 6 & 3 & 1 & I & 3 & 2 & 3 & I & 7 & 3 \\
\hline \multicolumn{15}{|c|}{ Knew the cause of their most recent sore throat $(\mathrm{N}=5196)$} \\
\hline Know for sure & 22 & 21 & 24 & 29 & 16 & 19 & 16 & 21 & 22 & 42 & 17 & 23 & 18 & 24 \\
\hline Think/have a good idea & 50 & 44 & 52 & 41 & 50 & 52 & 67 & 59 & 60 & 39 & 57 & 54 & 34 & 46 \\
\hline Have no idea & 27 & 36 & 24 & 30 & 34 & 30 & 17 & 20 & 19 & 19 & 27 & 22 & 48 & 30 \\
\hline \multicolumn{15}{|c|}{ Perceived/known cause of their most recent sore throat $(n=3775)^{a}$} \\
\hline Common cold/flu & 41 & 36 & 38 & 42 & 27 & 40 & 43 & 48 & 50 & 49 & 35 & 40 & 43 & 36 \\
\hline Cold/wet weather & 34 & 15 & 25 & 25 & 35 & 41 & 39 & 28 & 42 & 44 & 34 & 47 & 20 & 36 \\
\hline Fatigue & 21 & 15 & 15 & 26 & 17 & 15 & 9 & 42 & 22 & 10 & 20 & 44 & 19 & 20 \\
\hline Other bacterial/viral infection & 19 & 17 & 15 & 16 & 8 & 16 & 14 & 36 & 25 & 21 & 25 & 27 & 11 & 12 \\
\hline Dust & 19 & 14 & 33 & 14 & 6 & 10 & 12 & 43 & 8 & 16 & 21 & 32 & 7 & 20 \\
\hline Air conditioning & 17 & 13 & 31 & 5 & 15 & 11 & 18 & 19 & 7 & 30 & 23 & 27 & 10 & 13 \\
\hline Pollution & 17 & 9 & 27 & 26 & 10 & 5 & 14 & 24 & 10 & 18 & 18 & 32 & 9 & 15 \\
\hline Stress (home/work) & 15 & 10 & 20 & 10 & 8 & 12 & 12 & 36 & 16 & 10 & 18 & 17 & 10 & 15 \\
\hline Smoking (including passive) & 15 & 13 & 10 & 21 & 10 & 15 & 14 & 16 & 18 & 9 & 14 & 19 & 13 & 21 \\
\hline Hay fever & 9 & 12 & 33 & 5 & 4 & 5 & 1 & 4 & 3 & 3 & 19 & 4 & 10 & 15 \\
\hline
\end{tabular}

Note: aSubset of respondents who answered that they "knew for sure" or had a "good idea" about the cause of their most recent sore throat.

Abbreviations: AUS, Australia; BR, Brazil; CH, China; FR, France; GE, Germany; IT, Italy; PH, the Philippines; RU, Russia; KSA, Saudi Arabia; SA, South Africa; TH, Thailand; UK, the United Kingdom; USA, the United States of America. 
Table 4 Self-Management for Sore Throat

\begin{tabular}{|c|c|c|c|c|c|c|c|c|c|c|c|c|c|c|}
\hline \multirow[t]{2}{*}{ Survey Item } & \multicolumn{14}{|c|}{ Responses, \% } \\
\hline & Overall & AUS & BR & $\mathbf{C H}$ & $\mathbf{F R}$ & GE & IT & PH & RU & KSA & SA & TH & UK & USA \\
\hline \multicolumn{15}{|c|}{ Seeking treatment for their last sore throat $(\mathrm{N}=5196)$} \\
\hline $\begin{array}{l}\text { Actively sought out treatment or help } \\
\text { with symptoms }\end{array}$ & 89 & 78 & 91 & 90 & 83 & 90 & 95 & 96 & 89 & 98 & 82 & 96 & 81 & 88 \\
\hline \multicolumn{15}{|c|}{ Main reasons for taking action to treat their last sore throat $(n=46 \mid 7)$} \\
\hline Did not want symptoms to get worse & 48 & 45 & 48 & 35 & 46 & 53 & 48 & 66 & 52 & 24 & 52 & 63 & 40 & 46 \\
\hline Symptoms interfered with daily life & 32 & 24 & 33 & 35 & 26 & 25 & 18 & 53 & 47 & 24 & 33 & 45 & 25 & 29 \\
\hline Symptoms interfered with sleep & 32 & 28 & 32 & 31 & 37 & 28 & 26 & 44 & 27 & 28 & 31 & 42 & 28 & 29 \\
\hline Symptoms were not going away & 31 & 37 & 33 & 28 & 28 & 29 & 31 & 21 & 34 & 20 & 35 & 33 & 39 & 42 \\
\hline Symptoms were very unpleasant & 29 & 34 & 38 & 21 & 38 & 39 & 29 & 22 & 34 & 12 & 31 & 28 & 23 & 30 \\
\hline Symptoms were agonizing & 21 & 12 & 16 & 32 & II & 25 & 4 & 22 & 22 & 34 & 15 & 40 & 11 & 17 \\
\hline \multicolumn{15}{|c|}{ Main treatment for the throat symptoms most recently experienced $(n=4617)$} \\
\hline Medicated sore throat remedies & 36 & 37 & 39 & 26 & 38 & 42 & 45 & 13 & 44 & 42 & 37 & 27 & 42 & 33 \\
\hline Drinking water/fluids & 14 & 15 & 8 & 21 & 5 & 19 & 4 & 38 & 5 & 5 & 8 & 22 & 11 & 19 \\
\hline Antibiotics & 12 & 9 & 15 & 10 & 6 & 6 & 12 & 14 & 15 & 21 & 17 & 14 & 5 & 9 \\
\hline Analgesics/pain killers & 9 & 12 & 9 & 6 & 13 & 4 & 18 & 5 & 4 & 9 & 8 & 6 & 20 & 10 \\
\hline Prescription treatment & 9 & 4 & 10 & 18 & 9 & 4 & 5 & 8 & 12 & 12 & 11 & 12 & 5 & 4 \\
\hline Home remedies & 8 & 12 & 10 & 7 & 10 & 10 & 5 & 5 & 9 & 5 & 10 & 10 & 6 & 10 \\
\hline Natural/alternative treatment & 8 & 6 & 6 & 7 & 12 & 11 & 8 & 14 & 9 & 4 & 6 & 6 & 4 & 6 \\
\hline Confectionery, sweets, chewing gum & 2 & 2 & I & 5 & 3 & 4 & I & I & I & I & 3 & 2 & 5 & 2 \\
\hline Other & 2 & 3 & 2 & I & 2 & 1 & 1 & 2 & I & 0 & 1 & I & 2 & 6 \\
\hline
\end{tabular}

Abbreviations: AUS, Australia; BR, Brazil; CH, China; FR, France; GE, Germany; IT, Italy; PH, the Philippines; RU, Russia; KSA, Saudi Arabia; SA, South Africa; TH, Thailand; UK, the United Kingdom; USA, the United States of America.

sources of advice (Figure 2A). All sources of information were used across all perceived severity classes. For example, the internet was also used for very severe symptoms and HCPs were also consulted for mild symptoms. Pharmacists or GPs were most commonly consulted first when advice was sought from an HCP (Figure 2B). Overall, perceived severity did not appear to influence which HCP was consulted first. Of those respondents who consulted a specialist first, a slightly higher proportion experienced very severe sore throat (18\%), compared to those consulting another HCP first (10-14\%).

The reliance on different HCPs varied between countries. Respondents who consulted a GP ranged from $14 \%$ in the UK to $45 \%$ in Italy, while those who consulted a specialist ranged from $4 \%$ in the UK, France and Italy to $38 \%$ in China. When asked about why they had visited their doctor, $90 \%$ (strongly) wanted "to receive an explanation for possible treatments" (Figure 2C). Over 80\% wanted to know how serious the problem was, to be examined for the cause, to acquire pain relief and to find out how quickly they would recover. The highest levels of utilization of pharmacy personnel for advice were in Thailand (66\%) and South Africa (61\%), with the lowest in Russia (27\%) and the UK and USA (28\% each). Overall, the majority (76\%) of respondents (strongly) agreed that they valued the advice of pharmacy personnel (range, $62 \%$ in Russia to $91 \%$ in Saudi Arabia) but only half (53\%) felt that pharmacy personnel could tell them the cause of the sore throat (range, $40 \%$ in Russia to $85 \%$ in Saudi Arabia [Figure 2D]).

Differences between countries were also noted when comparing which HCP was consulted first, with respondents in Russia (57\%), Italy (50\%) and Australia (49\%) heavily favoring a GP/doctor, compared with respondents in China, where they favored specialists (44\%). Respondents in the UK (67\%), France (56\%) and Saudi Arabia (56\%) were most likely to consult pharmacy personnel first, whereas respondents in the Philippines (24\%) and China (32\%) were least likely.

The highest proportions of respondents not seeking HCP advice were in the UK (50\%) and Australia (43\%), with the lowest proportions occurring in the Philippines 
A

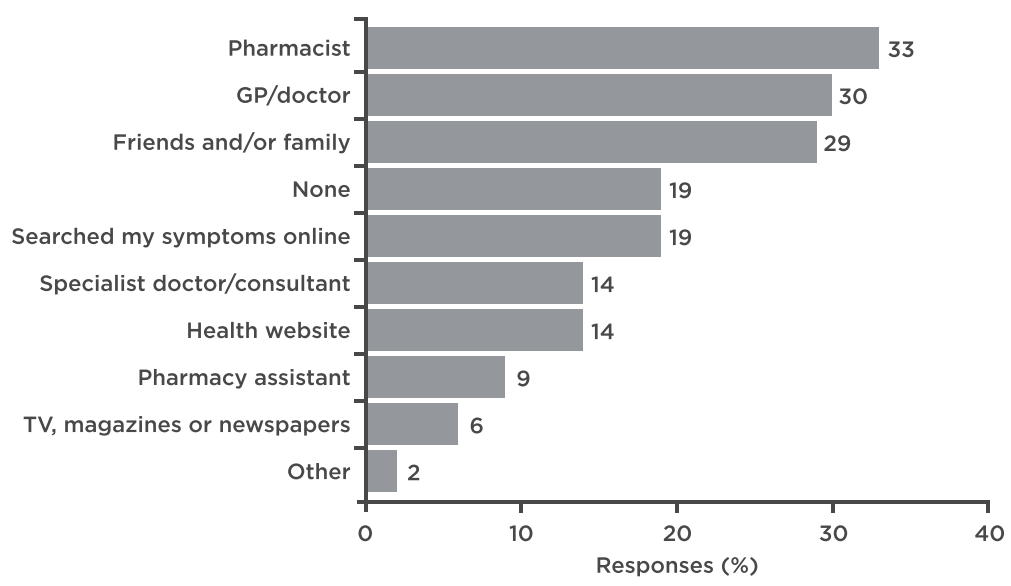

B

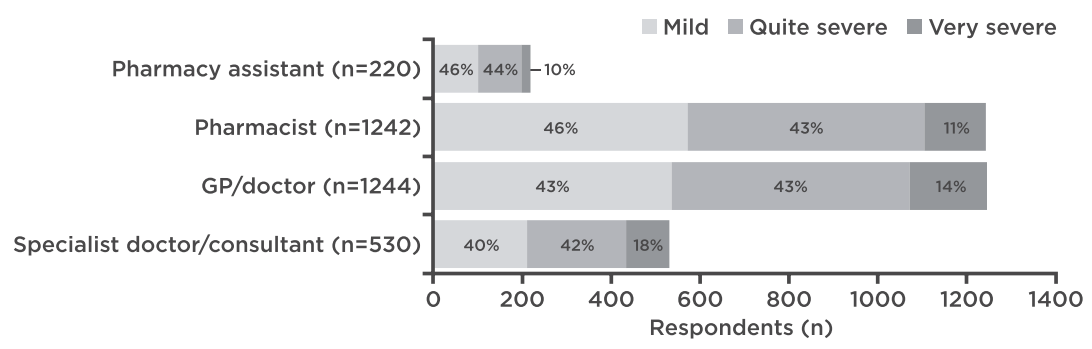

C

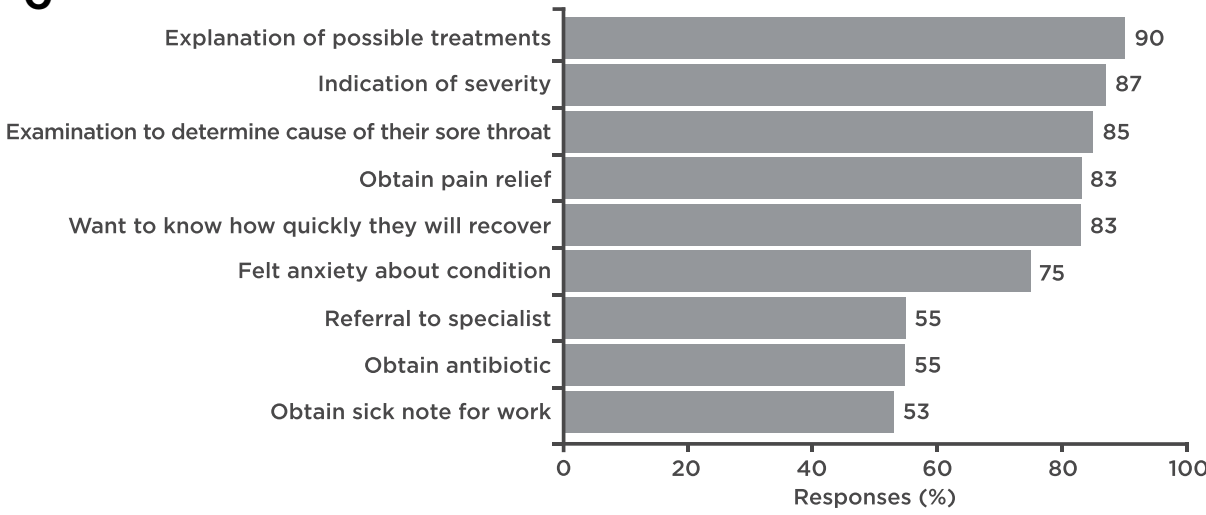

D

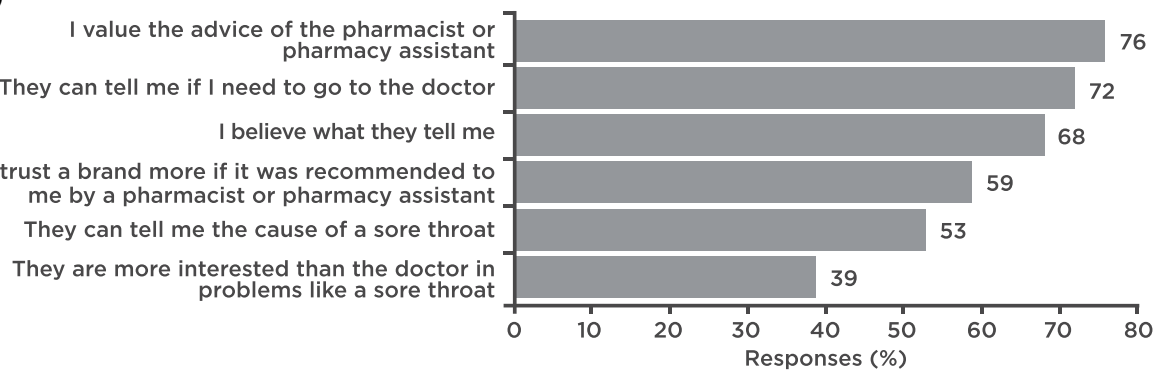

Figure 2 Sources of advice, reasons for visiting a doctor for sore throat and evaluation of advice. (A) Sources of advice for 5196 survey participants. Question: "Which of these, if any, did you go to for advice when you experienced your most recent throat symptoms?" (multiple responses allowed). (B) Healthcare professional consulted first for advice in 3236 survey participants. Question: "Which of the healthcare professionals did you go to for advice first?" (single response), and severity of sore throat "How would you describe the severity of the sore or dry throat that you suffered most recently?" (rated from very mild to very severe on a I0-point Likert scale). (C) Reasons for visiting a doctor for sore throat in 2040 survey participants. Question: "How strongly do you agree or disagree with the following statements about why you visited your doctor?" (single response to each statement allowed; "[Strongly] agree" responses plotted). (D) Evaluation of advice offered by pharmacy personnel when consulted for treatment of sore throat in 5196 survey participants. Question: "Thinking now about pharmacist/pharmacy assistants, how strongly do you agree or disagree with the following statements?" (single response to each statement allowed; “[Strongly] agree” responses plotted). 


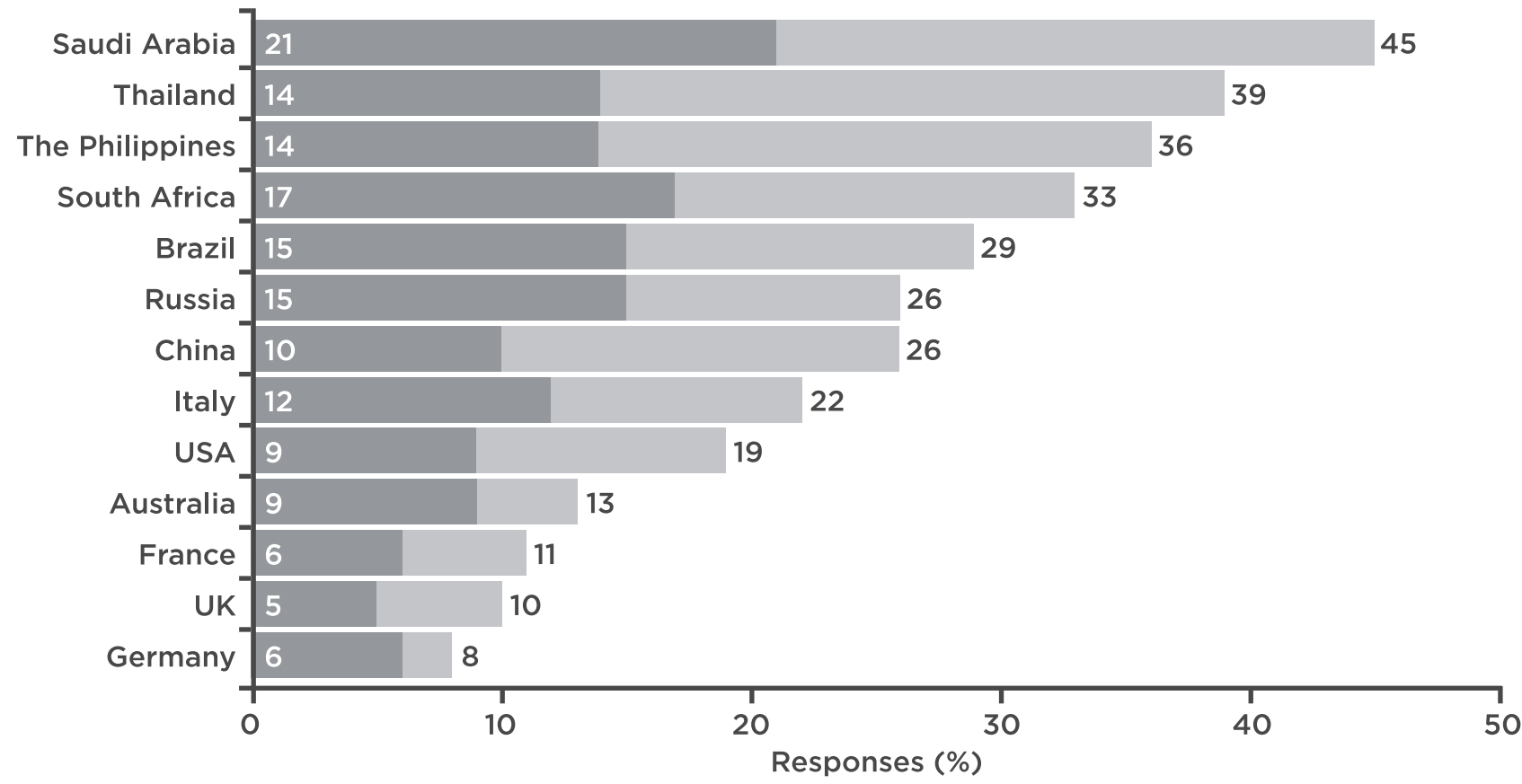

Figure 3 Use of antibiotics for sore throat. Response "Antibiotic" to the question "Which of these do/did you use for the throat symptoms you experienced most recently?" (multiple responses allowed), and response "Antibiotics" to the question "And which would you say was your MAIN treatment?" (single response allowed).

$(2 \%)$ and Thailand $(2 \%)$. When asked why they did not visit an HCP about their sore throat, most respondents $(60 \%)$ thought that it was not serious enough (range, $28 \%$ in Saudi Arabia to $75 \%$ in Thailand).

\section{Antibiotic Use for Sore Throat}

The percentage of respondents using antibiotics for sore throat varied widely between countries (Figure 3).

To "relieve pain" was the second most common reason for using antibiotics (48\%), while to "treat infection" was the most common reason (63\%) (Supplementary file 3).

\section{Attitudes Towards the Use of Antibiotics for Sore Throat}

"Wanting an antibiotic" was rated much lower than most other reasons for visiting a doctor (Figure 2C), but varied widely between countries. The percentages of responses of "(Strongly) agree" for wanting an antibiotic were lowest in Russia (24\%) and France (31\%), and highest in the USA (73\%) and Saudi Arabia (82\%).

Respondents were generally aware that antibiotics should only be used if necessary (average, 87\%; range, $63 \%$ in the Philippines to $96 \%$ in Russia) and that unnecessary use can reduce their effectiveness (average, $82 \%$; range, $66 \%$ in Thailand to $87 \%$ in Australia). However, there was considerably more variation in the proportion of respondents who thought that antibiotics would be effective against sore throat (average, 53\%; range, $24 \%$ in France to $94 \%$ in Saudi Arabia), and whether respondents thought that antibiotics could prevent worsening of symptoms (average, $32 \%$; range $12 \%$ in Germany to $77 \%$ in Saudi Arabia). With the exception of patients in France, the UK and Germany, $>50 \%$ of respondents thought that the use of antibiotics would accelerate recovery of sore throat (average, 63\%).

The majority of antibiotics were acquired "at the pharmacy" (65\%), with high percentages for Saudi Arabia (91\%) and Russia (86\%), while as few as $25 \%$ of respondents in China did likewise. Although online acquisition was overall low $(6 \%)$, a high percentage of respondents from the USA (38\%) and Australia (25\%) used this channel to obtain antibiotics. Only $1 \%$ used antibiotics that they already owned (Italy 11\%, China 6\%, Saudi Arabia $2 \% ; 0 \%$ for all other countries).

Differences were observed between countries in their belief, request for and use of antibiotics for sore throat (Figure 4). 


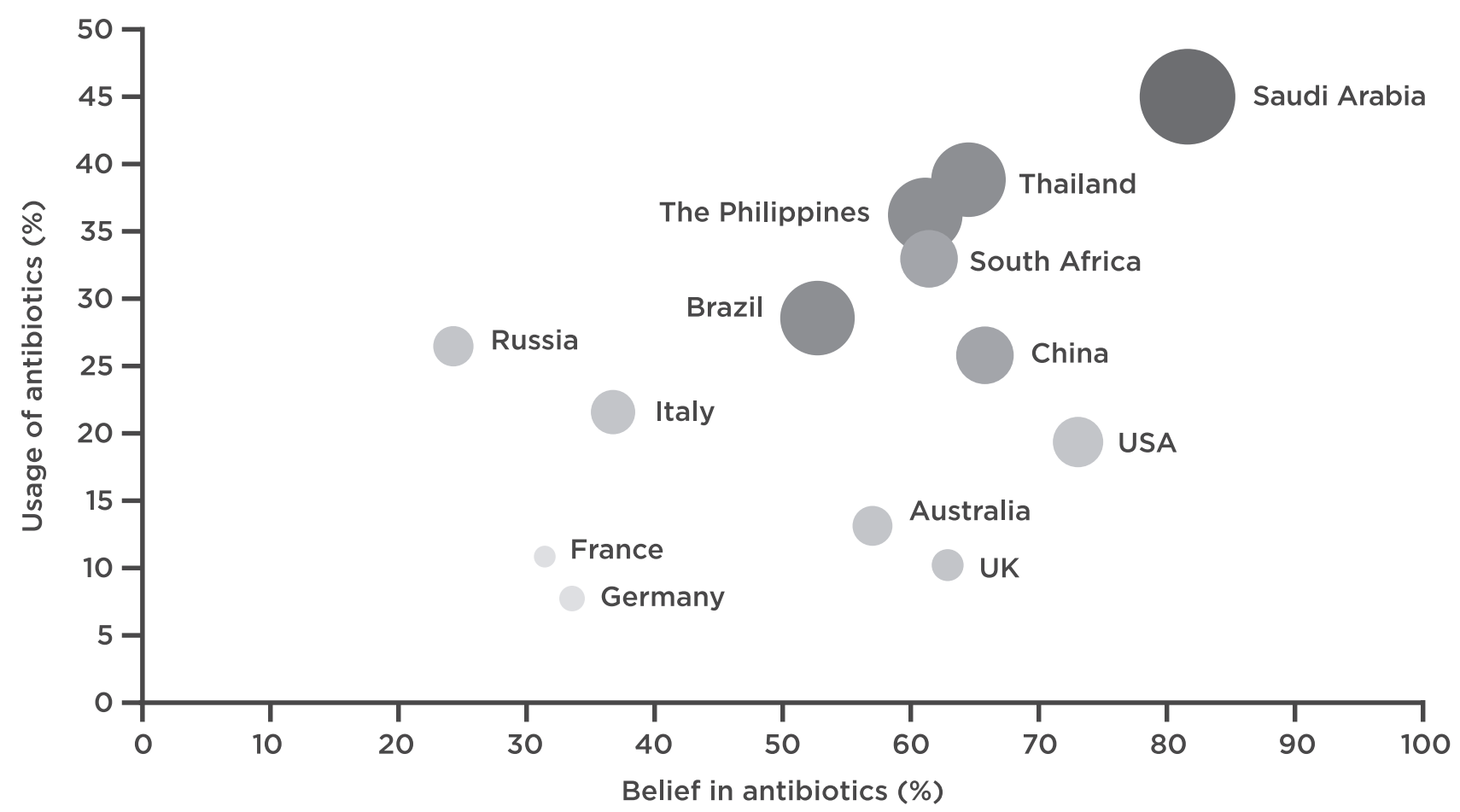

Figure 4 Belief in, use of and desire for antibiotics to treat sore throat. Response "Antibiotics" to the question "Which of these do/did you use for the throat symptoms you experienced most recently?" (number of respondents: 4617) against the (strongly) agree response "want an antibiotic" to the question "How strongly do you agree or disagree with the following statements about why you visit your doctor?" (number of respondents: 2040). The width of the bubbles/bubble color corresponds to the number of people who (strongly) agreed that "Antibiotics are generally effective against sore throats" (number of respondents: 5 I82).

Respondents in France and Germany expressed the lowest level of belief that antibiotics are effective against sore throat, second and third lowest proportion of requests for antibiotics from the doctor, and the third and first lowest proportion using antibiotics for sore throat. Respondents in the UK, Australia and the USA expressed relatively low belief that antibiotics are effective against sore throat (30-49\%) and relatively low use (10-19\%), but had high proportions of people requesting antibiotics for this ailment (57-73\%). In Italy and Russia, despite relatively low proportions of people requesting antibiotics and believing that they are effective for sore throat, the reported use of antibiotics was higher (22\% and $26 \%$, respectively) than in countries with similar levels of belief in and desire for antibiotics. Respondents from Saudi Arabia and Thailand had the highest use of antibiotics for sore throat ( $45 \%$ and 39\%, respectively), and most respondents from these countries held the belief that antibiotics help sore throat and requested antibiotics from their doctor.

\section{Discussion}

\section{Summary of Main Findings}

The results indicate that respondents were proactive when seeking treatment or help for sore throat. The desire to limit the worsening of symptoms was the main reason for seeking treatment, and medicated sore throat remedies were the principal method of treatment. There was considerable variation in the proportion of respondents who desire and use antibiotics for sore throat, and believe that they are effective.

\section{Comparison with Existing Literature}

The main reasons for consulting a doctor were to understand what caused the sore throat, to discuss treatment options, to obtain symptomatic relief and to seek reassurance, but not to obtain antibiotics, in agreement with previous research in this setting. ${ }^{15,17}$ However, reported use of antibiotics for sore throat was generally high, albeit markedly different between countries, perhaps 
indicating the need for more patient education on antibiotics and awareness of the consequences of their inappropriate use. The variation in use reported herein could in part be driven by differences in the epidemiology of bacterial throat infections, ${ }^{18}$ but more likely by HCPand patient-related factors driving inappropriate antibiotic prescribing and use. ${ }^{19,20}$ Despite the existence of international and national guidelines for the management of sore throat, ${ }^{21-25}$ a sizeable proportion of antibiotic prescriptions do not comply with guidelines. ${ }^{26,27}$ Socio-economic characteristics and socio-cultural patient behaviors, such as uncertainty avoidance (the extent to which a society tolerates uncertainty and ambiguity) and masculinity (assertive and competitive traits), have been associated with inappropriate antibiotic use. ${ }^{20,28}$ For example, while both France and Italy have high uncertainty avoidance Hofstede scores, Italy has a higher masculinity score than France, ${ }^{28}$ which supports the data showing higher antibiotic use in Italy in this study. Countries with high masculinity tend to have a strong work ethic and may therefore incorrectly consider antibiotics to be an essential tool to support a rapid return to work. ${ }^{28}$

A recent meta-analysis of 38 studies from 24 countries revealed that antibiotics are frequently supplied without prescription in many countries. ${ }^{29}$ Our survey did not distinguish between antibiotics obtained with and without prescription. In particular, the non-prescription supply of antibiotics was frequent in Saudi Arabia, which would likely contribute to the high rate of use of antibiotics observed in that country.

It may be presumed that the belief that antibiotics are effective in the treatment of sore throat would be closely associated with the desire for antibiotics and subsequent use. Although this relationship was observed for some countries, such as Thailand and Saudi Arabia, there were notable exceptions. Interestingly, countries such as France, Germany and the UK, which had a comparable level of use of antibiotics for sore throat, in agreement with recent European data, ${ }^{30}$ differed markedly in their desire for antibiotics.

Awareness that antibiotics should only be used when necessary was high but knowledge of their effectiveness for sore throat, given that sore throats are commonly viral in origin, ${ }^{10}$ varied considerably between countries, in agreement with previous data in this context. ${ }^{30,31}$

\section{Strengths and Limitations}

This study provides insight into how behaviors and attitudes towards antibiotic management of sore throat differ between countries. These data will support interventional development to appropriately target key country-specific behaviors and attitudes that will allow the greatest reduction in antibiotic use and improve patient management.

Use of the quota sampling method for each country ensured that the sample was representative of the general population for the specified demographics. However, its generalizability may not extend to other criteria. Notably, the survey was targeted at adults and did not address the pediatric population, which may present with different parental behaviors. Although the countries surveyed have differing levels of healthcare access/quality ${ }^{32}$ and education standards, ${ }^{33}$ most rank relatively highly for these variables. It is unclear whether the findings reported would also be applicable to populations in countries with lower healthcare or socio-economic standards.

A few other limitations should be acknowledged. First, as respondents were asked about sore throat symptoms within the past 12 months, there is potential for recall bias. Second, no cognitive testing was carried out on the survey questions prior to implementation. It is therefore possible that cognitive factors (eg understanding of the question and ability to provide meaningful answers based on the response options) could have impacted the validity and reliability of the study. Third, this study was an anonymous market research survey, in line with the definition of market research in the EphMRA Code of Conduct 2019. This type of research does not require Clinical Research Ethics Committee approval; this lack of peer review prior to data collection could be considered a limitation.

\section{Implications for Clinical Practice}

The value of the GP as an antibiotic steward can be clearly seen in our findings. In the UK, USA, China and Australia, doctors were able to maintain lower antibiotic use despite working with patient populations that present with high rates of antibiotic-seeking behavior. As reliance on doctors tended to be higher in countries where the use of antibiotics is also high, materials and strategies that target improved patient management are likely to have a bigger impact in those countries.

Respondents in Thailand and the Philippines had comparable levels of desire to obtain antibiotics with those in the UK, but use of antibiotics for sore throat was notably 
higher. Better diagnostic aids and treatment algorithms to reduce uncertainty and stronger controls on access to antibiotics would be helpful in this setting.

Training of physicians in advanced communication skills, decision-support tools and educational strategies has been shown to reduce antibiotic prescribing rates significantly $^{34}$ and reduce the inappropriate use of antibiotics. $^{35}$ The Global Respiratory Infection Partnership (GRIP) has developed a toolkit ${ }^{36}$ that targets policy, prevention, the prescriber, pharmacy and patients. ${ }^{37}$ In a small-scale study, antibiotic prescribing for sore throat was reduced by $50 \%$ after the introduction of the toolkit. ${ }^{38}$

Modifying the habits and perceptions of HCPs to ensure that they address the real concerns of their patients, openly explore patient expectations, provide reassurance and explain the various symptomatic relief options, such as analgesics, ${ }^{39}$ will be key to reducing the inappropriate use of antibiotics in primary care and contributing towards effective antibiotic stewardship. ${ }^{37,38,40}$ As use of antibiotics is also driven in part by patient behavior, ${ }^{20}$ it is vital that strategies to reduce inappropriate antibiotic use for sore throat target both areas. The data described herein support this approach by elucidating differences in behaviors and attitudes that may exist at the country level, thus allowing targeted approaches to be developed. By informing HCPs on how to improve rational antibiotic prescribing for sore throat, their value as antibiotic stewards is improved, and patients can be directed towards proven methods of symptomatic relief.

\section{Conclusions}

Attitudes towards antibiotics for sore throat varied considerably between countries. Our results should enable HCPs to better anticipate patients' needs. This awareness should support HCPs in their role as antibiotic stewards, helping them to reduce the misuse of antibiotics and further guiding patients towards symptomatic self-management of sore throat.

\section{Abbreviations}

GP, general practitioner; HCP, healthcare professional.

\section{Data Sharing Statement}

The data collected for this study are available from Reckitt Benckiser Healthcare Ltd, UK. Restrictions apply to the availability of these data, which were used under license for the current study, and so are not publicly available. Data are, however, available from Adrian Shephard upon reasonable request and with permission of Reckitt Benckiser Healthcare Ltd, UK.

\section{Ethics Approval and Informed Consent}

No ethics approval was sought for this survey, conducted in 2017, as it involved market research. All responses in this non-interventional survey were collected anonymously, with the written or verbal informed consent of participants. Participant recruitment, database management and the survey process were conducted in compliance with the Market Research Society's Code of Conduct (London UK).

\section{Consent for Publication}

Not applicable.

\section{Acknowledgments}

We would like to thank Alison Barnes (Incite Marketing Planning, London, UK) for her assistance with the survey. Medical writing assistance was provided by Iain D. Barrett, $\mathrm{PhD}$ and Corrinne Segal, $\mathrm{PhD}$ (Elements Communications Ltd, Westerham, UK) and funded by Reckitt Benckiser Healthcare Ltd, UK.

\section{Author Contributions}

All authors contributed to data analysis, drafting or revising the article, gave final approval of the version to be published, and agree to be accountable for all aspects of the work.

\section{Funding}

This work was supported by Reckitt Benckiser Healthcare Ltd, UK, which was involved in the design and interpretation of data for this study.

\section{Disclosure}

AV, AuS, AA and AP are members of the Global Respiratory Infection Partnership (supported by an unrestricted educational grant from Reckitt Benckiser Healthcare Ltd, UK). AV reports grants from Reckitt Benckiser, during the conduct of the study; AS is a full-time employee of Reckitt Benckiser Healthcare Ltd, UK and reports an unrestricted educational grant from Reckitt Benckiser, during the conduct of the study. The authors report no other potential conflicts of interest for this work. 


\section{References}

1. Goossens H, Ferech M, Vander Stichele R, Elseviers M, Group EP. Outpatient antibiotic use in Europe and association with resistance: a cross-national database study. Lancet. 2005;365(9459):579-587. doi:10.1016/S0140-6736(05)70799-6

2. Riedel S, Beekmann SE, Heilmann KP, et al. Antimicrobial use in Europe and antimicrobial resistance in Streptococcus pneumoniae. Eur J Clin Microbiol Infect Dis. 2007;26(7):485-490. doi:10.1007/ s10096-007-0321-5

3. Ventola CL. The antibiotic resistance crisis: part 1: causes and threats. Pharm Ther. 2015;40(4):277-283.

4. Almagor J, Temkin E, Benenson I, Fallach N, Carmeli Y. DRIVE-AB consortium. The impact of antibiotic use on transmission of resistant bacteria in hospitals: insights from an agent-based model. PLoS One. 2018;13(5):e0197111. doi:10.1371/journal.pone.0197111

5. European Centre for Disease Prevention and Control. Annual epidemiological report for 2017: antimicrobial consumption. Available from https://www.ecdc.europa.eu/sites/portal/files/documents/ESAC-NETreportAER-2017-updated.pdf. Accessed March 25, 2020.

6. Organisation for Economic Co-operation and Development. Health at a Glance 2017. Available from: https://www.oecd-ilibrary.org/docserver/ health_glance-2017-en.pdf?expires $=1564581889 \& \mathrm{id}=\mathrm{id} \&$ accname $=$ guest \&checksum=52E9026B59B6292F1C83CA919ADD8756. Accessed March 25, 2020

7. World Health Organization. Antibiotic resistance. 2018. Available from: http://www.who.int/en/news-room/fact-sheets/detail/antibioticresistance. Accessed March 25, 2020

8. Worrall GJ. Acute sore throat. Can Fam Physician. 2007;53(11):19611962.

9. Dolk FCK, Pouwels KB, Smith DRM, Robotham JV, Smieszek T. Antibiotics in primary care in England: which antibiotics are prescribed and for which conditions? J Antimicrob Chemother. 2018;73 (2):ii2-ii10. doi:10.1093/jac/dkx504

10. Ebell MH, Smith MA, Barry HC, Ives K, Carey M. The rational clinical examination. Does this patient have strep throat? JAMA 2000;284(22):2912-2918. doi:10.1001/jama.284.22.2912

11. Spinks A, Glasziou PP, Del Mar CB. Antibiotics for sore throat. Cochrane Database Syst Rev. 2013;11:CD000023.

12. Little P, Dorward M, Warner G, Stephens K, Senior J, Moore M. Importance of patient pressure and perceived pressure and perceived medical need for investigations, referral, and prescribing in primary care: nested observational study. BMJ. 2004;328(7437):444. doi:10.1136/bmj.38013.644086.7C

13. Fletcher-Lartey S, Yee M, Gaarslev C, Khan R. Why do general practitioners prescribe antibiotics for upper respiratory tract infections to meet patient expectations: a mixed methods study. $B M J$ Open. 2016;6(10):e012244. doi:10.1136/bmjopen-2016-012244

14. Butler CC, Rollnick S, Pill R, Maggs-Rapport F, Stott N. Understanding the culture of prescribing: qualitative study of general practitioners' and patients' perceptions of antibiotics for sore throats. BMJ. 1998;317(7159):637-642. doi:10.1136/bmj.317.7159.637

15. van Driel ML, De Sutter A, Deveugele M, et al. Are sore throat patients who hope for antibiotics actually asking for pain relief? Ann Fam Med. 2006;4(6):494-499. doi:10.1370/afm.609

16. van der Velden AW, Bell J, Sessa A, Duerden M, Altiner A. Sore throat: effective communication delivers improved diagnosis, enhanced self-care and more rational use of antibiotics. Int J Clin Pract Suppl. 2013;67(180):10-16. doi:10.1111/ijcp.12336

17. Freidoony L, Kim CB, Haghani H, et al. From visiting a physician to expecting antibiotics: korean perspectives and practices toward respiratory tract infections. JKMS. 2017;32(2):278-286. doi:10.3346/jkms.2017.32.2.278
18. World Health Organization. The current evidence for the burden of group A streptococcal diseases. 2005. Available from: https://apps. who.int/iris/bitstream/handle/10665/69063/WHO_FCH_CAH_05.07. pdf;jsessionid=8DE4593D21 ACB33F6806937661C985A9? sequence $=1$. Accessed March 25, 2020.

19. Flottorp SA, Oxman AD, Krause J, et al. A checklist for identifying determinants of practice: a systematic review and synthesis of frameworks and taxonomies of factors that prevent or enable improvements in healthcare professional practice. Implement Sci. 2013;8:35. doi:10.1186/1748-5908-8-35

20. Zanichelli V, Tebano G, Gyssens IC, et al. Patient-related determinants of antibiotic use: a systematic review. Clin Microbiol Infect. 2019;25(1):48-53. doi:10.1016/j.cmi.2018.04.031

21. Pelucchi C, Grigoryan L, Galeone C, et al. Guideline for the management of acute sore throat. Clin Microbiol Infect. 2012;18(Suppl 1):128. doi:10.1111/j.1469-0691.2012.03766.x

22. Chiappini E, Regoli M, Bonsignori F, et al. Analysis of different recommendations from international guidelines for the management of acute pharyngitis in adults and children. Clin Ther. 2011;33(1):4858. doi:10.1016/j.clinthera.2011.02.001

23. Snow V, Mottur-Pilson C, Cooper RJ, Hoffman JR. for the American College of Physicians-American Society of Internal Medicine. Principles of appropriate antibiotic use for acute pharyngitis in adults. Ann Intern Med. 2001;134(6):506-508. doi:10.7326/0003-4819-1346-200103200-00018

24. Thamlikitkul V, Apisitwittaya W. Implementation of clinical practice guidelines for upper respiratory infection in Thailand. Int $J$ Infect Dis. 2004;8(1):47-51. doi:10.1016/j.ijid.2003.09.001

25. Shulman ST, Bisno AL, Clegg HW, et al. Clinical practice guideline for the diagnosis and management of group A streptococcal pharyngitis: 2012 update by the Infectious Diseases Society of America. Clin Infect Dis. 2012;55(10):e86-102. doi:10.1093/cid/ cis629

26. Urkin J, Allenbogen M, Friger M, Vinker S, Reuveni H, Elahayani A Acute pharyngitis: low adherence to guidelines highlights need for greater flexibility in managing paediatric cases. Acta Paediatr. 2013;102(11):1075-1080. doi:10.1111/apa.12364

27. Stuhr JK, Lykkegaard J, Kristensen JK, Kornum JB, Hansen MP. Danish GPs' and practice nurses' management of acute sore throat and adherence to guidelines. Fam Pract. 2018;36(2):192-198. doi:10.1093/fampra/cmy059

28. Borg MA. National cultural dimensions as drivers of inappropriate ambulatory care consumption of antibiotics in Europe and their relevance to awareness campaigns. $J$ Antimicrob Chemother. 2012;67(3):763-767. doi:10.1093/jac/dkr541

29. Auta A, Hadi MA, Oga E, et al. Global access to antibiotics without prescription in community pharmacies: a systematic review and metaanalysis. J Infect. 2019;78(1):8-18. doi:10.1016/j.jinf.2018.07.001

30. European Commission. Antimicrobial resistance (Special Eurobarometer 445). 2016. Available from: https://ec.europa.eu/ health/amr/sites/amr/files/eb445_amr_generalreport_en.pdf. Accessed March 25, 2020.

31. World Health Organization. Antibiotic resistance: multi-country public awareness survey. 2015. Available from: https://apps.who.int/iris/ handle/10665/194460. Accessed March 25, 2020.

32. GBD. 2016 Healthcare Access and Quality Collaborators. Measuring performance on the Healthcare Access and Quality Index for 195 countries and territories and selected subnational locations: a systematic analysis from the Global Burden of Disease Study 2016. Lancet. 2018;391(10136):2236-2271.

33. United Nations Development Programme. Human development reports: education index. 2013. Available from: http://hdr.undp.org/ en/content/education-index. Accessed March 25, 2020 
34. Cals JWL, Butler CC, Hopstaken RM, Hood K, Dinant G-J. Effect of point of care testing for $\mathrm{C}$ reactive protein and training in communication skills on antibiotic use in lower respiratory tract infections: cluster randomised trial. BMJ. 2009;338:b1374. doi:10.1136/bmj.b1374

35. Drekonja DM, Filice GA, Greer N, et al. Antimicrobial stewardship in outpatient settings: a systematic review. Infect Control Hosp Epidemiol. 2015;36(2):142-152. doi:10.1017/ice.2014.41

36. Global Respiratory Infection Partnership. Available from: https://www. grip-initiative.org/resources/1-2-3-resources/. Accessed March 25, 2020.

37. Essack S, Pignatari AC. A framework for the non-antibiotic management of upper respiratory tract infections: towards a global change in antibiotic resistance. Int J Clin Pract Suppl. 2013;67(180):4-9. doi:10.1111/ijcp.12335
38. Altiner A, Bell J, Duerden M, et al. More action, less resistance: report of the 2014 summit of the Global Respiratory Infection Partnership. Int $J$ Pharm Pract. 2015;23(5):370-377. doi:10.1111/ijpp.12177

39. Klimek L, Sperl A. Pharmacy based sore throat therapy according to current guidelines. Med Monatsschr Pharm. 2015;38(12):503-508.

40. van der Velden A, Duerden MG, Bell J, et al. Prescriber and patient responsibilities in treatment of acute respiratory tract infections essential for conservation of antibiotics. Antibiotics. 2013;2(2):316327. doi:10.3390/antibiotics 2020316

\section{Publish your work in this journal}

Pragmatic and Observational Research is an international, peerreviewed, open access journal that publishes data from studies designed to reflect more closely medical interventions in realworld clinical practice compared with classical randomized controlled trials (RCTs). The manuscript management system is completely online and includes a very quick and fair peer-review system. Visit http://www.dovepress.com/testimonials.php to read real quotes from published authors. 